\title{
Making progress on the global crisis of obesity and weight management
}

\author{
Food and obesity are undoubtedly linked but the relation is complex. Michael Lean and colleagues discuss what we \\ know, and what we don't know, about weight management
}

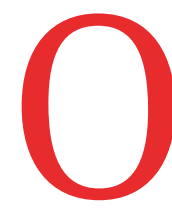
besity is an unsolved crisis, generating long term distress and disabilities, reducing human capital, and increasing disease burdens and healthcare costs globally. Obesity has a complex aetiology, incurring controversies within both scientific and media arenas. ${ }^{1}$ Poor education and socioeconomic situations are important drivers of severe obesity, confounding country analyses by racial or ethnic groups. Data collected by EUROSTAT show wide variations in prevalences of people with a body mass index (BMI) $>30$ across European states. ${ }^{2}$ Age is important: by age $65-70$, as many as $40 \%$ of all people in the $\mathrm{UK}$ reach a $\mathrm{BMI}>30$, and $80 \%$ have a $\mathrm{BMI}>25 .{ }^{3}$ Many with $\mathrm{BMI}>30$ will experience secondary medical consequences, although overall life expectancies of populations have increased steadily despite obesity and the disabilities it brings.

Many factors have been associated with weight gain, difficulty achieving and maintaining weight loss, and secondary medical consequences of obesity. Some

\section{KEY MESSAGES}

- The balance between calorie intake and calorie expenditure determines body weight and body fat changes

- Different foods influence total energy consumption by modifying appetite, or by affecting energy expenditure, eg through diet induced thermogenesis

- Overweight people generally consume more food energy (calories) than thinner people to maintain their higher body weight weight

- Any diet plan that an individual is able to adhere to will cause weight loss, but different dietary patterns may influence adherence to different degrees in different subgroups

- Weight loss maintenance is a greater challenge than weight loss for many people because it requires adapting to permanently eating less energy despite living with in the same physical, social, cultural, and educational environments in which they developed obesity have causal influences, many are innocent bystanders, and some have no basis in science. We focus on those related to food.

\section{Energy balance: is a calorie always a calorie?}

The energy equation-that calories consumed=calories expended $+/$ - calories stored (as body fat or glycogen)-is always true. Obesity develops if absorbed dietary energy (calories) from foods exceeds energy expenditure for a considerable period (box 1). Similarly, excess body fat is lost if energy intake falls below expenditure. However, numerous multilevel factors contribute to determining energy expenditure, intake, and absorption, and small mismatches with food consumption over a long period can lead to large cumulative weight changes.

Obesity is best considered not just as a state of excess of body fat or body mass index above an arbitrary cut-off, but as the disease process, of excess body fat accumulation that has interacting (epi-) genetic and environmental causes and multiple pathological consequences. ${ }^{5}$ Although obesity tracks in families and has relatively high heritability, ${ }^{6}$ intensive searches for genetic factors have been unfruitful, but environmental drivers may be augmented by epigenetic changes. Given that $20-30 \%$ of entire populations have become obese in only 50 years, the dominant cause of the current obesity epidemic clearly lies in environmental factors.

\section{Science and controversies linking food, obesity, and weight management}

Although declining physical inactivity contributes to obesity in populations, possibly through a disconnect between energy expenditure and appetite when physical activity falls below an individual threshold, ${ }^{78}$ we consider here only the role of food.

Different aspects of the influences of specific foods on obesity are often confused. In some cases, commercial or political interests have distorted evidence and muddied the water. Individual foods seldom influence obesity. Instead, we consider food groups, overall diets, and the patterns of eating within them, resulting from food

\section{Box 1: Energy balance explained}

Each kg of adipose tissue contains about $7000 \mathrm{kcal}$. Thus consuming just $100 \mathrm{kcal} \mathrm{a}$ day more than energy expenditure for a year could result in a gain of $5 \mathrm{~kg}$ adipose tissue $(100 \times 365 / 7000)$. A continued excess of half that size would be enough to reach $40-50 \mathrm{~kg}$ weight gain over 20-30 years. However, energy expenditure is not fixed and varies with diet and with weight changes:

- At any weight, a person whose body weight and physical activity remain stable must consume the same number of calories as are expended

- As weight (body mass) increases, basal metabolism and the cost of carrying the extra weight in activities both rise gradually, roughly in proportion to the weight gain. ${ }^{4}$ So continued weight gain will occur only if the calories consumed continue to rise

- During active weight loss, basal metabolic rate falls and physical activity becomes more efficient, so fewer calories are expended in proportion to weight loss. Additionally, severe negative energy balance (ie, undereating) produces exaggerated adaptive changes. These changes protected people against food shortages during evolution, such that consuming a fixed calorie deficit below the baseline energy expenditure will lead to weight loss but with a plateau. For continued weight loss, to treat obesity, energy intake must fall further to remain at a level below the reduced energy expenditure. $^{4}$

choices or restrictions. Diets are analysed in terms of their macronutrient contents (fat, protein, and carbohydrate), micronutrients (vitamins, minerals), and other bioactive molecules and food properties (eg, fibre and whole grain). A "healthy" diet (which confers health and helps prevent chronic diseases) will not necessarily prevent or treat obesity. Conversely, diets containing fewer calories may not always be healthy.

Managing obesity demands understanding how nutrients and diet compositions, foods, eating patterns, food cultures, and political and commercial systems are responsible for weight gain and obesity, and how they can contribute to effective weight loss and prevent 
weight regain. These elements (table 1) are not necessarily the same, and complex influences also consider potential effects on general health, and risks of other diseases. Effective public recommendations for weight loss or to avoid weight gain are all likely to also reduce the risks of secondary conditions such as diabetes, cardiovascular diseases, cancer, arthritis, depression, and dementia.

The lack of objective ways to establish what people are actually eating is a major problem for human nutrition and clinical sciences. Substantial misreporting of food consumption is usual, particularly underreporting among people with obesity. Despite stated motivation to lose weight, and expert professional support, people often find it hard to change eating behaviours and revert towards their previous habitual diets. Changing the behaviours people consider normal is difficult, as a general principle. This is particularly true for diet because of the strong biological reward system that facilitates eating. Whether eating, or overeating, should be considered addictive is debated. There are at least parallels, with food cravings characteristically for energy dense foods that facilitate overeating, ${ }^{9}$ and some of the neural mechanisms behind normal repetitive eating behaviours are shared with classical addictions. The evidence in more in keeping with a normal addiction to eating as a survival mechanism, which is sometimes exaggerated, than with true addictions to specific foods. ${ }^{10}$

\section{Individual willpower versus societal responsibilities: gluttony and sloth?}

The "victim blaming" view that individuals are responsible for their afflictions has vary between subgroups. For each, we must

been persistent and destructive. Although some people at risk can resist obesity through vigilance, external factors are hard to overcome. Evidence indicates a recent environmentally led global epidemic, mediated by obesogenic factors such as frequent eating out, large portion sizes, and the commercial normalisation of routinely consuming high sugar, high fat snacks and sweetened drinks between meals.

Sustained conscious effort and willpower are needed to lose weight and not regain it when food is easily available. However, that does not imply that lack of individual willpower-gluttony and sloth-is the cause or that insufficient motivation and engagement explains the failures of interventions. Hunger, greed, and temptation are sensations originating in the unconscious brain, which are affected by the food environment in ways that are resistant to willpower: the sight or smell of attractive food triggers a cascade of hormone and sympathetic nervous system responses that increase hunger and desire to eat. Thus calorie cutting strategies that increase hunger tend to fail because willpower is ineffective over the more potent lower brain functions. Individually directed willpower centric approaches towards prevention will therefore almost inevitably fail while the food environment is unregulated. Collective responsibility is therefore required for effective progress at a population level (box 2).

\section{Current controversies in food and obesity Eat less, or exercise more?}

Many lay people believe that exercise is essential or sufficient for weight loss. However, although exercise has a small weight loss benefit when combined with an

\begin{tabular}{|c|c|c|}
\hline Roles of food and diet & Strategy & Comment \\
\hline $\begin{array}{l}\text { Prevent weight gain } \\
\text { (body fat gain) }\end{array}$ & Long term, population directed & $\begin{array}{l}\text { Food and diet may have specific effects on metabolism } \\
\text { or on appetite, generally for all people or for definable } \\
\text { subgroups (personalised weight maintenance or } \\
\text { obesity prevention diets) }\end{array}$ \\
\hline Weight loss (body fat loss) & Short term, individual & $\begin{array}{l}\text { Weight loss is aimed mainly at providing a vehicle to } \\
\text { deliver the least number of calories for the longest } \\
\text { possible time, for the greatest number of people to } \\
\text { achieve targets. Individual preferences and cultures } \\
\text { as well as metabolic charactistics mean that different } \\
\text { foods and diets are preferred and more effective for } \\
\text { some people }\end{array}$ \\
\hline $\begin{array}{l}\text { Prevent weight regain } \\
\text { (body fat regain) }\end{array}$ & Long term, individual & $\begin{array}{l}\text { In general, this role is likely to be similar to preventing } \\
\text { weight gain }\end{array}$ \\
\hline \multicolumn{2}{|l|}{$\begin{array}{l}\text { Optimal health for overweight/ } \\
\text { obese people during: }\end{array}$} & \multirow{4}{*}{$\begin{array}{l}\text { Nutrient content of the diet is less relevant or critical } \\
\text { for health during short term weight loss, except for } \\
\text { specific issues (eg, preventing gallstones by providing } \\
\text { adequate dietary fat, postural hypotension by } \\
\text { providing sufficient sodium and water) and for specific } \\
\text { situations (eg, obese people with poor nutritional } \\
\text { status preparing for surgery, where deficiencies of } \\
\text { vitamin Cor Mg might be problems) }\end{array}$} \\
\hline Preventing weight gain & Long term & \\
\hline Weight loss & Short term & \\
\hline Preventing weight regain & Long term & \\
\hline
\end{tabular}

\section{Box 2: Failures of willpower centric view}

- National behavioural recommendations for weight management are largely based on application of willpower and are poorly accepted because they are (accurately) viewed as difficult and ineffective

- Uniquely for a major disease causing multiple pathologies, the prevailing perception of obesity is as a cost to healthcare and a burden on society, rather than its disabling and distressing effect on individuals

- There is insufficient investment in effective treatments for obesity, thus numerous profitable non-evidence-based approaches are promoted, with inflated claims to meet popular desire for easier weight control

- Intense media coverage of commercial "treatments" that are not evidence based or are minimally effective contribute to mass confusion and undermine professional advice

- The view that food companies are not responsible for the obesity epidemic leaves them free to create and promote an increasing variety of tempting obesogenic products

- Less obesogenic food products tend to be more expensive per calorie, which is a barrier to population shifts towards healthier eating habits

- Willpower centricity leads to an underdevelopment of population directed measures that avoid individual accountability

- Government funding for obesity treatment is less than for other diseases relative to numbers of resulting disability or death ${ }^{11}$

energy restricted food plan, ${ }^{12}$ neither aerobic nor resistance exercise in typical amounts are effective as a sole strategy. ${ }^{13}{ }^{14}$ Recognising that reducing energy intake has the central role in weight loss and prevention of regain will help prevent discouragement and recidivism. Physical activity has a modestly greater role in maintain weight loss ${ }^{1516}$ and undoubted value for long term health and preserving muscle mass. ${ }^{17}$

\section{How many calories are needed for health and weight management?}

The calorie requirements of adult humans are lower now than in the past. US reference values for healthy adult men and women in energy balance are 2500 and $2000 \mathrm{kcal} / \mathrm{day}$ respectively. Adults who are overweight or obese typically have higher (not lower) calorie requirements than those who are not obese. ${ }^{18}$ During acute negative energy balance (such as on a restricted diet), energy expenditure is reduced substantially, by about $15 \%-30 \%$ on 
average, ${ }^{1920}$ but contrary to widespread belief, once someone has stopped losing weight, energy requirements are decreased relatively little, in direct proportion to weight loss. ${ }^{21}$ The challenge of sustainable weight loss, therefore, is to reduce food intake below the already low normal energy requirements and then to maintain a permanently lower energy intake afterwards to prevent weight regain. This is difficult for people who have become obese leading what they have regarded as normal lives, when living under the same obesogenic conditions.

Historically, the prevailing advice for weight management has been to introduce a modest reduction in energy intake, to lose weight gradually, and avoid extreme diets, which were believed to cause "rebound" weight regain to a higher than baseline level. Accumulating evidence now suggests that the best long term successes are often among people who engage well and lose weight successfully in the early stages, whether by eating food based diets or following intensive programmes with nutritionally complete formula diets. ${ }^{22}{ }^{23}$ No particular dietary method for long term maintenance has so far been shown to achieve superior results to others when implemented with appropriate support, but individuals may have diet preferences, for multiple reasons, which permit better outcomes.

\section{Special effect foods: are all calories equal?}

There is no evidence that any single food carries special risks of weight gain and obesity. Some people can lose weight, and avoid regain, by focusing on restricting specific foods or food groups, including (for different people) bread and cereals, red meats or meat products, cakes and confectionery, milk and dairy foods, sugar, and alcohol. These strategies are effective for weight control as long as the foods are rich sources of energy, consumed frequently by the individual, easily identified, and their avoidance tolerated without compensation from other foods. However, such restrictive diets can be difficult to maintain because dietary variety seems to be innately attractive, persuasively marketed, and tends to increase energy consumption. ${ }^{24}$ Broader measures, such as veganism, avoiding all packaged foods, or all gluten containing foods, can also help weight control, but these measures can lead to undesirable nutritional consequences-for example, iodine deficiency if dairy or seafoods are not consumed, or thiamine deficiency from avoiding cereals. ${ }^{25}$

Macronutrients and foods differ in their effects on appetite and satiation and on thermogenesis and in how efficiently they are digested. Thus, the total calories in a food are not the same as the calories available and absorbed after eating. For example, high protein diets reduce appetite more than other macronutrients, a potential hazard for people who are underweight ${ }^{26}$ but a benefit for those wishing to lose weight. There is a hierarchy of obligatory diet induced thermogenesis from macronutrients (protein $>$ carbohydrate $>$ fat), so high protein and whole grain foods increase postprandial metabolism more than foods higher in carbohydrate or fat. ${ }^{26-28}$ Foods rich in various fibres, dairy foods such as milk and yoghuts (perhaps related to calcium content), ${ }^{29}$ and with structural integrity that resist digestion such as nuts, all show reduced absorption of energy from the gastrointestinal tract, likely by reducing the efficiency of fat absorption. ${ }^{30}$ However, these are relatively small effects, easily overwhelmed by factors such as portion size, ${ }^{31}$ so should not be considered in isolation when determining dietary recommendations.

\section{Sugar and obesity}

The role of sugar in obesity is hotly debated and much misunderstood. Sugar provides $3.75 \mathrm{kcal} / \mathrm{g}$ and has a relatively low GI. However, it is not essential to human diets, and its consumption, particularly in sweetened drinks between meals and in snack foods combined with fat $(9 \mathrm{kcal} / \mathrm{g})$, has risen steeply worldwide in parallel with rising rates of obesity. ${ }^{32}$ Nevertheless, it is difficult to establish a causal relation between sugar consumption and obesity: much of the published research has been observational, and "reverse causality" may apply. ${ }^{33} 34$

The media are giving increasing attention to the view that sugar is uniquely to blame for obesity and its metabolic complications, based on the effect of glucose in raising serum insulin, which promotes fat synthesis. Some have extended this concern to all forms of carbohydrate. However, meta-analysis of randomised controlled trials and prospective cohort studies finds only modest effects. Design of randomised trials can affect the conclusions. For example, in studies into the effects of removing sugar from the diet the control group can either continue with the extra calories from sugar or remove the equivalent number of calories from another food source, and choosing fats or protein sources will affect outcomes. Alternatively, the intervention group may have the sugar calories replaced with calories from another source to the same level as controls. These manipulations are hard to interpret because changing the amount of one nutrient inevitably changes the proportions and metabolic influences or others and from the entire diet. In summary, the evidence is that adding a calorie source such as sugar will cause weight gain and adverse metabolic effects, cutting a calorie source such as sugar or sugar sweetened drinks reduces weight gain by $2-3 \mathrm{~kg}$, but there is no detectable sugar specific effect on body weight, because body weight does not change when sugar is removed from the diet and replaced with the same calories from other carbohydrates. ${ }^{35} 36$

There is ongoing debate about whether sugar in liquids may bypass energy regulation and appetite control mechanisms. If consumed in large amounts, sugar increases weight by a small amount in overweight people. ${ }^{37}$ A systematic review of all studies lasting over three weeks concluded that sugar sweetened drinks had no overall effect on the obesity epidemic, but they may pose difficulties once people had obesity. ${ }^{38} \mathrm{~A}$ six month randomised controlled trial in people who were overweight found that adding one litre a day of a sugar sweetened beverage increased visceral fat, liver and muscle fat, and also raised triglycerides and total cholesterol, compared with a similar artificially sweetened drink, water, and milk. ${ }^{39}$

As well as being a calorie source, sugar may also have indirect influences on appetite and eating. Evidence in humans is weak, but frequent exposure to highly sweetened drinks and foods may induce tolerance to unnatural sweetness and so facilitate weight gain by promoting consumption of very sweet, energy dense foods. ${ }^{4041}$ In real life, a common dietary pattern associated with obesity is characterised by frequent consumption of sweetened drinks and sugary-fatty snacks between meals: theses habits are recent, heavily promoted by social marketing, and tend to travel together. Taxation on sugar sweetened drinks has led to greater promotion and consumption of artificially sweetened alternatives, but it is not yet known if that will reduce weight gain. ${ }^{42}$

Fructose (50\% of table sugar or honey, and enriched in corn syrup sweeteners) is sweeter than glucose, so has been proposed as a calorie saving alternative to glucose or sucrose. However, it has several adverse metabolic effects when consumed in large amounts, including preferential de novo lipogenesis, lipoprotein remodelling, adverse changes in body fat distribution and low density lipoprotein fractions, and increased insulin resistance. These effects appear only when fructose is consumed as $25 \%$ of dietary 
energy, which would not occur if sucrose is its source, but could be a problem with high intakes of corn syrup. ${ }^{43}$

\section{Intermittent fasting}

Total fasting depletes essential nutrients and is unsustainable. Well designed intermittent modified fasting regimens for weight control ${ }^{44}$ reflect many long established religious practices and probably match conditions experienced throughout human evolution. Several models are under investigation, including alternate day fasting or 5:2 diet regimens, usually with "fasting" days restricted to about $500 \mathrm{kcal}$ and either usual eating or some form of conventional healthy diet on other days. Current evidence suggests similar weight losses in completers but higher drop-out than with constant daily restriction. ${ }^{45}$ Flexible approaches to suit individual preferences may be appropriate, but better long term evidence is needed for effectiveness and safety of intermittent fasting for maintaing weight.

\section{Reducing dietary carbohydrate or fat?}

Arguments abound as to whether carbohydrates or fats are to blame for obesity. Some carbohydrates act as a more potent stimulus for insulin, possibly to promote fat deposition, but fats contain two to three times as many calories per gram as carbohydrate and are more readily stored as body fat, without raising metabolic rate. Epidemiological and long term intervention studies are heavily confounded by other factors that also influence energy balance. For example, higher fat intakes are found in wealthier countries, where obesity is more common. Overweight people may consume more carbohydrate but must also eat more calories overall, and they commonly underreport their food consumption selectively. ${ }^{4647}$ Advice to restrict carbohydrate may be more effective in reducing energy consumption in populations where a high proportion of carbohydrate is visible as sugar, and with manufactured foods which also contain fat, whereas the fat content of foods is often more difficult to identify.

Evidence comparing low carbohydrate and low fat diets is not entirely consistent. A careful meta-analysis of 32 studies of isocaloric exchange between fat and carbohydrate concluded that the loss of body fat and increase in energy expenditure are slightly better with low fat diets. ${ }^{48}$ However, longer term studies show better weight loss outcomes for both low carbohydrate and low fat diets when compared with habitual diet, with little difference between the two in weight and body fat loss. ${ }^{49-51}$ Other meta-analyses find about $2 \mathrm{~kg}$ greater loss of body fat with low carbohydrate diets and also improved cardiometabolic risk factors, ${ }^{52}$ but the effect sizes are generally small. The apparently conflicting outcomes of meta-analyses may be explained by differences in inclusion criteria for diets, study design, how the other dietary components of the diets were changed, and the characteristics of participants (box 3).

An isocaloric exchange design is less clinically relevant to the real life situation, where most of the effects of dietary composition on weight loss are indirect, through differential effects on hunger and satiety. It is also relevant that a very low carbohydrate diet will deplete body glycogen stores, which necessarily incurs a loss of the $2 \mathrm{~kg}$ of water that is combined with glycogen ${ }^{53}$ and probably also reduces capacity for physical activity. Concerns have been raised that publication bias may favour studies supporting lower carbohydrate $\operatorname{diet}^{\mathrm{s}} 54$

\section{Personalised dietary management based on genetic or metabolic status?}

Emerging evidence suggests that genetic or metabolic factors may affect a person's weight loss responsiveness to carbohydrate, such that normoglycaemic people achieve greater satiety on low fat diets despite a higher glycaemic load (GL), whereas more insulin resistant people do better with lower GLs. ${ }^{55}$ Specifically, people who are more insulin resistant or diabetic may lose more weight, with benefits for glucose control, lipid levels, and blood pressure, when assigned to lower glycaemic load regimens. ${ }^{56}$ A low GL can be achieved either by selecting a diet that is lower in total carbohydrate or by choosing low glycaemic index (GI) carbohydrates. These findings may help explain discrepant results across different populations with different dietary profiles of carbohydrates, as well as assist personalisation of weight management regimens. The results are broadly consistent with another study in people with type 2 diabetes showing that even high carbohydrate consumptions of up to $65 \%$ of dietary energy can have metabolic benefit for glycaemia and lipids if the carbohydrate is largely from amylose rich wholegrain and legume sources. ${ }^{57-60}$ These diets have not been studied for long periods to establish effects on weight. More evidence is required to define the best range of carbohydrate intakes to recommend on metabolic grounds for people with type 2 diabetes, or whether personal choice may
Box 3: Factors affecting outcome of meta-analyses

- Inclusion criteria-Diets referred to as "low carbohydrate" range from $15 \%$ to $45 \%$ of energy from carbohydrate

- Study design-Isocaloric diets administered under controlled metabolic ward conditions provide information on biological and metabolic effects, whereas studies under free living conditions and diets tell us about effects mediated by, or limited by, changes in appetite

- Modification of dietary componentsProtein, fat, and fibre contents of the diet have different metabolic and satiating influences, and they also interact within a food matrix to affect palatability

- Characteristics of participantsInnumerable factors can modify how a particular diet composition will affect weight change in different individuals, including age, sex, smoking, and acquired knowledge, beliefs and attitudes towards foods and diet composition

be the dominant influence for long term adherence and weight control.

A recent large 12 month trial comparing healthy low fat and healthy low carbohydrate diets in overweight adults reported weight losses of 5-6 kg in both groups, with no significant difference in weight change between the two diets. In this study neither the presence of genes that have been proposed to confer benefit from low carbohydrate diets, nor baseline insulin secretion, helped to define which diet was better for specific subgroups, but low adherence to the diet prescriptions may have masked any possible effects. ${ }^{61}$

The evidence is incomplete, but it suggests that people with normal insulin sensitivity can achieve marginally greater success on low fat regimens, provided very high GLs are avoided. However insulin resistance or diabetes exaggerates the responses to glycaemic loads, making lower total carbohydrate intakes preferable in most cases since this is easier than adhering to a higher carbohydrate regimen with the necessary large amounts of dietary fibre and legumes. ${ }^{56263}$ These different dietary patterns still need to be compared in randomised trials, but outcomes seem likely to be affected more by adherence in real life settings, which in turn will relate to the effectiveness of behavioural support and cultural and social factors, than by individual underlying biology.

\section{Feeding the microbiota to combat obesity?} Evidence is emerging that organisms in the gut may have a role in obesity. ${ }^{64}$ The 
gut microbiota in rodents can affect the efficacy of energy harvest from feed and affects secretion of gastrointestinal appetite hormones. In humans, certain bacteria metabolise dietary fibre to short chain fatty acids that are absorbed to provide fuel for the gut itself (2-3 kcal/g), and act as insulin sensitisers and satiety stimulants. ${ }^{65} \mathrm{~A}$ Prevotella driven enterotype is predominant in people consuming more carbohydrate and fibre ${ }^{66}$ and seems to help weight control. In a randomised trial, participants with high ratio of Prevotella spp to Bacteroides spp (P:B) experienced a $3.5 \mathrm{~kg}$ greater weight loss over 26 weeks on a Mediterranean/Nordic style diet (high in fibre and wholegrain) than those on an average Danish diet, whereas no weight loss difference was observed among people with low P:B. ${ }^{67}$ The success of people with high $\mathrm{P}: \mathrm{B}$ ratio is dependent on a high dietary fibre intake. ${ }^{63}$ It remains to be determined if these associations are on the causal pathway, but the $\mathrm{P}: \mathrm{B}$ ratio may prove predictive of successful weight loss.

\section{Evolution, weight cycling and "paleo" diets}

Assumptions that our evolutionary ancestors did not experience obesity, and rarely developed type 2 diabetes or other complications of overweight, have led to a profusion of popular diets based on notions about their eating patterns. Beliefs about high fat, high meat, low carbohydrate 'paleo' diets have attracted media interest. Evidence from archaeology, ethnology, biochemistry, physiology, and anatomy are not persuasive that this was the usual diet of human ancestors, and the life expectancy of palaeolithic ancestors was short-an insecure basis for modern dietary recommendations.

Humans do not have specialised carnivore anatomy but do possess the high levels of amylase necessary to digest starchy foods, and require dietary fibre and retrograded starch to maintain a healthy microbiome. While our ancestors were clearly omnivorous, evidence on hunter gatherers, even before agrarian settlement, points to considerable reliance on aquatic and plant foods. ${ }^{68}$ As an example, the residual hunter forager Tsimane people of Bolivia, who have no obesity, diabetes, or cardiovascular disease, follow a very high carbohydrate plant based diet (73\% of energy).$^{69}$ This demands, and supports, much more physical activity, averaging 10-15 000 steps/day, which allows appetite to match requirement better ${ }^{8}$ than in modern populations. Humans probably had to adapt to seasonal and intermittent periods of food shortage during evolution, with different metabolic and behavioural strategies, some individuals responding by conserving energy and others by risking energy expenditure to seek foods.

Although we may have adapted through evolution to cope well with short-term and seasonal food shortages, body weight fluctuations may still harm longterm health. There is no convincing evidence that weight cycling from intentional dieting is a hazard for cardiovascular health, but there may be greater loss of bone mass than is restored during weight regain, and weight cycling has been associated with a more android body fat distribution and is linked with polycystic ovary syndrome. ${ }^{70}$ Major weight loss will reduce fertility in normal weight women, but paradoxically it can restore fertility to many obese women.

The global obesity epidemic, dating only from the 1970s-90s in different countries, reflects multiple changes beyond the conditions to which humans adapted during evolution, with huge reductions in physical activity, an absence of food shortages, large out-of-home meal portions, and effective promotion of energy consumption through eating outside meals. Occasional grazing, on available plant foods, has probably always been normal, but frequent large meals of varied energy dense foods and modern snacking on energy dense "snack foods" combining high GI carbohydrates and fat (such as ice cream and chips), and highly sweetened drinks, seems particularly hazardous. Although many conceptions of paleolithic eating are almost certainly wrong, any diet regimen that disallows modern facilitators of overeating, such as varied meals and snack foods, creates favourable conditions for effective weight loss as long as these prohibitions are followed.

\section{What policy actions are required?}

Lack of progress against the obesity epidemic has several origins. Research on obesity has been hampered by the assumption that the solution lies in advice or support for individual decision making. Importantly, funding for research and treatment will be more rationally planned if conditions such as type 2 diabetes, hypertension, arthritis, asthma, depression can be reframed as complications of obesity (the disease process, as defined above) rather than independent diseases. Research to contribute to effective ways to prevent and reverse obesity is needed on a truly global scale. Obesity is increasing everywhere, and the negative effects of obesity in one country are exported to others through increased greenhouse gas emissions and reduced national economic productivity.

Food is fundamental to the stable function of individuals, families, and society as well as to economies, so ethical and political aspects must be considered. WHO defined the critical threshold for malnutrition, demanding government intervention, as a $15 \%$ prevalence. Obesity prevalence has already exceeded $25 \%$ in many post-industrial countries, so interventions are overdue.

Interventions with the potential to be effective include those aimed at food marketing and taxing foods (or food groups) that are dominant contributors to weight gain, reducing the price of alternative less obesogenic food products, and curbing excessive portion sizes in restaurants. ${ }^{71}$ Existing legislation-for example, the EU Unfair Commercial Practices Directive-could be used against vendors of products with unsubstantiated and misleading claims (overt or implied) of effectiveness against obesity. ${ }^{72}$ Several countries have recently instituted taxes on sugar sweetened beverages. Evidence is accruing, from Mexico and elsewhere, that in the short term there are behavioural shifts away from taxed foods, ${ }^{42}$ but effects on weight gain or obesity have not yet been reported. The UK is beginning to tax sweetened drinks with sugar content above $8 \%$, encouraging product reformulation with sugar content falling from $10 \%$ to under $8 \%$.

One way for diet related health to be improved without widening health inequalities is through "health-by-stealth" approaches. This recognises that in addition to interventions aimed at individuals, there must be a permanent change to the food supply. This approach is in contrast to population directed educational methods, which preferentially benefit the better educated and better advantaged. To be effective, healthby-stealth approaches require reformulation of entire product portfolios, rather than just creating premium price "health foods" or low energy alternatives.

\section{Countering misinformation}

Many issues relating to the causes and treatment of obesity seem more controversial in the media than they are in the scientific community, partly because of commercial interests. While several emerging research fields offer new insights, and potential avenues for future action, uncontroversial opportunities for potentially effective and safe government intervention have existed for many years. ${ }^{73}$ Fiscal and other government-led initiatives could facilitate 
reduced consumption of highly energy dense foods and drinks of low nutritional value, discourage excessive portion sizes in foods and meals consumed away from home, and between meal consumption.

Misinformation is also a problem. Governments can build platforms to foster culturally appropriate ways to maintain and healthy weight without further disadvantaging the more disadvantaged in society, distribute responsible information about obesity prevention weight management, and support more research to identify effective interventions. Teaching about calories and energy balance early in schools, together with prominent, ubiquitous, calorie labelling of foods, could provide valuable effects at low cost. Combined, these multiple initiatives could have a major effect on the global obesity epidemic and human health.

Competing interests: We have read and understood BMJ policy on declaration of interests and declare the following: ML has received institutional research funds and support for meeting attendance from Diabetes UK, European Association for the Study of Obesity, Novo Nordisk, and Cambridge Weight Plan and pPersonal payments for advisory boards and consultancy from Novo Nordisk and Counterweight. AA is co-inventor on a pending provisional patent application on the use of biomarkers for prediction of weight loss responses, and co-founder/owner of the University of Copenhagen spin-out company Personalized Weight Management Research Consortium (Gluco-diet.dk). AA is consultant or a member of advisory boards for the following concerns with potential interest in the area: Basic Research, Beachbody; BioCare Copenhagen, Gelesis, Groupe Éthique et Santé, McCain Foods, Nestlé Research Center, and Weight Watchers. AA is coauthor of several diet and cookery books, including personalised nutrition for weight loss. SBR is founder of iDiet (www.theidiet.com) and coauthor of three books on healthy eating and weight management for adults and children. She has received institutional research funds from Nutrients and institutional royalty from Gelesis.

Provenance and peer review: Commissioned; externally peer reviewed.

This article is one of a series commissioned by The $B M$ J. Open access fees for the series were funded by Swiss Re, which had no input into the commissioning or peer review of the articles. The BM/ thanks the series advisers, Nita Forouhi and Dariush Mozaffarian, for valuable advice and guiding selection of topics in the series.

Michael E J Lean, professor $^{1}$

Arne Astrup, professor ${ }^{2}$

Susan B Roberts, professor ${ }^{3}$

${ }^{1}$ Human Nutrition, School of Medicine, Dentistry and

Nursing, University of Glasgow, Glasgow, UK

${ }^{2}$ Department of Nutrition, Exercise and Sports,

University of Copenhagen, Denmark

${ }^{3}$ Tufts University, Boston, MA, USA

Correspondence to:MEJ Lean mike.lean@glasgow.ac.uk

1 Casazza K, Fontaine KR, Astrup A, et al. Myths, presumptions, and facts about obesity. $N$ Engl J Med 2013;368:446-54. doi:10.1056/ NEJMsa1208051
2 Eurostat. Statistics explained. Proportion of overweight and of obese men. http://ec.europa.eu/eurostat/ statistics-explained/index.php?title=File:Proportion of_overweight_and_of_obese_men,_2014.png. 2014

3 Vlassopoulos A, Combet E, Lean MEJ. Changing distributions of body size and adiposity with age. Int J Obes (Lond) 2014;38:857-64. doi:10.1038/ ijo.2013.216

4 Ravussin E, Redman LM, Rochon J, et al, CALERIE Study Group. A 2-year randomized controlled trial of human caloric restriction: feasibility and effects on predictors of health span and longevity. J Gerontol A Biol Sci Med Sci 2015;70:1097-104. doi:10.1093/ gerona/glv057

5 Scottish Intercollegiate Guidelines Network (SIGN) 2010. Guideline 115: management of obesity. http:// www.sign.ac.uk/sign-115-management-of-obesity. html

6 Elder SJ, Roberts SB, McCrory MA, et al. Effect of body composition methodology on heritability estimation of body fatness. Open Nutr J 2012;6:48-58. doi:10.2174 /1874288201206010048

7 Mayer J, Marshall NB, Vitale JJ, Christensen JH, Mashayekhi MB, Stare FJ. Exercise, food intake and body weight in normal rats and genetically obese adult mice. Am J Physiol 1954;177:544-8. doi:10.1152/ ajplegacy.1954.177.3.544

8 Mayer J, Roy P, Mitra KP. Relation between caloric intake, body weight, and physical work: studies in an industrial male population in West Bengal. Am J Clin Nutr 1956;4:169-75. doi:10.1093/ajcn/4.2.169

9 Gilhooly CH, Das SK, Golden JK, et al. Food cravings and energy regulation: the characteristics of craved foods and their relationship with eating behaviors and weight change during 6 months of dietary energy restriction. Int J Obes (Lond) 2007;31:1849-58. doi:10.1038/sj.ijo.0803672

10 Hebebrand J, Albayrak Ö, Adan R, et al. "Eating addiction", rather than "food addiction", better captures addictive-like eating behavior. Neurosci Biobehav Rev 2014;47:295-306. doi:10.1016/j. neubiorev.2014.08.016

$11 \mathrm{NIH}$. Estimates of funding for various research, condition, and disease categories (RCDC). NIH Research Portfolio Online Reporting Tools (RePORT) 2018. https://report.nih.gov/categorical_spending. aspx

12 Foster-Schubert KE, Alfano CM, Duggan CR, et al. Effect of diet and exercise, alone or combined, on weight and body composition in overweightto-obese postmenopausal women. Obesity (Silver Spring) 2012;20:1628-38. doi:10.1038/ oby. 2011.76

13 Willis LH, Slentz CA, Bateman LA, et al. Effects of aerobic and/or resistance training on body mass and fat mass in overweight or obese adults. J App Physiol (1985) 2012;113:1831-7. doi:10.1152/ japplphysiol.01370.2011

14 Thorogood A, Mottillo S, Shimony A, et al. Isolated aerobic exercise and weight loss: a systematic review and meta-analysis of randomized controlled trials. Am J Med 2011;124:747-55. doi:10.1016/j. amjmed.2011.02.037

15 Kerns JC, Guo J, Fothergill E, et al. Increased physical activity associated with less weight regain six years after "the biggest loser" competition. Obesity (Silver Spring) 2017;25:1838-43. doi:10.1002/oby.21986

16 Fogelholm M, Kukkonen-Harjula K. Does physical activity prevent weight gain-a systematic review. Obes Rev 2000;1:95-111. doi:10.1046/j.1467789x.2000.00016.x

17 Chomentowski P, Dubé JJ, Amati F, et al. Moderate exercise attenuates the loss of skeletal muscle mass that occurs with intentional caloric restriction-induced weight loss in older, overweight to obese adults. J Gerontol A Biol Sci Med Sci 2009;64:575-80. doi:10.1093/gerona/glp007

18 Schoeller DA. Insights into energy balance from doubly labeled water. Int J Obes (Lond) 2008;32(Suppl 7):S72-5. doi:10.1038/ijo.2008.241
19 Bray GA. Effect of caloric restriction on energy expenditure in obese patients. Lancet 1969;2:397-8. doi:10.1016/S0140-6736(69)90109-3

20 Roberts SB, Fuss P, Heyman MB, Dallal GE, Young VR. Effects of age on energy expenditure and substrate oxidation during experimental underfeeding in healthy men. J Gerontol A Biol Sci Med Sci 1996;51:B158-66. doi:10.1093/gerona/51A.2.B158

21 Ravussin E, Redman LM, Rochon J, et al, CALERIE Study Group. A 2-year randomized controlled trial of human caloric restriction: feasibility and effects on predictors of health span and longevity. J Gerontol A Biol Sci Med Sci 2015;70:1097-104. doi:10.1093/ gerona/glv057

22 Astrup A, Rössner S. Lessons from obesity management programmes: greater initial weight loss improves long-term maintenance. Obes Rev 2000;1:17-9. doi:10.1046/j.1467789x.2000.00004.x

23 Nackers LM, Ross KM, Perri MG. The association between rate of initial weight loss and long-term success in obesity treatment: does slow and steady win the race? Int J Behav Med 2010;17:161-7. doi:10.1007/s12529-010-9092-y

24 McCrory MA, Fuss PJ, McCallum JE, et al. Dietary variety within food groups: association with energy intake and body fatness in men and women. Am J Clin Nutr 1999;69:440-7. doi:10.1093/ajcn/69.3.440

25 McKenna LA, Drummond RS, Drummond S, Talwar $D$, Lean ME. Seeing double: the low carb diet. BMJ 2013;346:f2563. doi:10.1136/bmj.f2563

26 Halton TL, Hu FB. The effects of high protein diets on thermogenesis, satiety and weight loss: a critical review. J Am Coll Nutr 2004;23:373-85. doi:10.1080/ 07315724.2004 .10719381

27 Mikkelsen PB, Toubro S, Astrup A. Effect of fat-reduced diets on 24-h energy expenditure: comparisons between animal protein, vegetable protein, and carbohydrate. Am J Clin Nutr 2000;72:1135-41. doi:10.1093/ajcn/72.5.1135

28 Karl JP, Meydani M, Barnett JB, et al. Substituting whole grains for refined grains in a 6-wk randomized trial favorably affects energy-balance metrics in healthy men and postmenopausal women. Am J Clin Nutr 2017;105:589-99. doi:10.3945/ ajcn.116.139683

29 Christensen R, Lorenzen JK, Svith CR, et al. Effect of calcium from dairy and dietary supplements on faecal fat excretion: a meta-analysis of randomized controlled trials. Obes Rev 2009;10:475-86. doi:10.1111/ j.1467-789X.2009.00599.x

30 Novotny JA, Gebauer SK, Baer DJ. Discrepancy between the Atwater factor predicted and empirically measured energy values of almonds in human diets. Am J Clin Nutr 2012;96:296-301. doi:10.3945/ ajcn.112.035782

31 Rolls BJ, Morris EL, Roe LS. Portion size of food affects energy intake in normal-weight and overweight men and women. Am J Clin Nutr 2002;76:1207-13. doi:10.1093/ajcn/76.6.1207

32 Malik VS, Popkin BM, Bray GA, Després JP, Hu FB. Sugar-sweetened beverages, obesity, type 2 diabetes mellitus, and cardiovascular disease risk. Circulation 2010;121:1356-64. doi:10.1161/ CIRCULATIONAHA.109.876185

33 Drewnowski A. Food perceptions and preferences of obese adults: a multidimensional approach. Int J Obes 1985;9:201-12.

34 Drewnowski A, Brunzell JD, Sande K, Iverius $\mathrm{PH}$, Greenwood MR. Sweet tooth reconsidered: taste responsiveness in human obesity. Physiol Behav 1985;35:617-22. doi:10.1016/0031 9384(85)90150-7

35 Saris WH, Astrup A, Prentice AM, et al. Randomized controlled trial of changes in dietary carbohydrate/ fat ratio and simple vs complex carbohydrates on body weight and blood lipids: the CARMEN study. The Carbohydrate Ratio Management in European National diets. Int J Obes Relat Metab Disord 2000;24:1310-8. doi:10.1038/sj.ijo.0801451 
36 Te Morenga L, Mallard S, Mann J. Dietary sugars and body weight: systematic review and meta-analyses of randomised controlled trials and cohort studies. BM/ 2012;346:e7492. doi:10.1136/bmj.e7492

37 Raben A, Vasilaras TH, Møller AC, Astrup A. Sucrose compared with artificial sweeteners: different effects on ad libitum food intake and body weight after $10 \mathrm{wk}$ of supplementation in overweight subjects. Am J Clin Nutr 2002;76:721-9. doi:10.1093/ajcn/76.4.721

38 Mattes RD, Shikany JM, Kaiser KA, Allison DB. Nutritively sweetened beverage consumption and body weight: a systematic review and meta-analysis of randomized experiments. Obes Rev 2011;12:346-65. doi:10.1111/j.1467-789X.2010.00755.x

39 Maersk M, Belza A, Stødkilde-Jørgensen $\mathrm{H}$, et al. Sucrose-sweetened beverages increase fat storage in the liver, muscle, and visceral fat depot: a 6-mo randomized intervention study. Am J Clin Nutr 2012;95:283-9. doi:10.3945/ajcn.111.022533

40 Lean ME, Te Morenga L. Sugar and Type 2 diabetes. BrMed Bull 2016;120:43-53. doi:10.1093/bmb/ Idw037

41 Faculty of Public Health. A duty on sugar sweetened beverages: a position statement. 2013. http://www. fph.org.uk/uploads/Position\%20statement\%20-\%20 SSBs.pdf

42 Lancet Diabetes Endocrinology. Sweet success: will sugar taxes improve health? Lancet Diabetes Endocrinol 2017;5:235. doi:10.1016/S22138587(17)30070-0

43 Stanhope KL, Schwarz JM, Keim NL, et al. Consuming fructose-sweetened, not glucose-sweetened, beverages increases visceral adiposity and lipids and decreases insulin sensitivity in overweight/ obese humans. / Clin Invest 2009;119:1322-34. doi:10.1172/JCl37385

44 Patterson RE, Laughlin GA, LaCroix AZ, et al. Intermittent fasting and human metabolic health. J Acad Nutr Diet 2015;115:1203-12. doi:10.1016/j. jand.2015.02.018

45 Trepanowski JF, Kroeger CM, Barnosky A, et al. Effect of Alternate-Day Fasting on Weight Loss, Weight Maintenance, and Cardioprotection Among Metabolically Healthy Obese Adults: A Randomized Clinical Trial. JAMA Intern Med 2017;177:930-8. doi:10.1001/jamainternmed.2017.0936

46 Lara JJ, Scott JA, Lean ME. Intentional mis-reporting of food consumption and its relationship with body mass index and psychological scores in women. J Hum Nutr Diet 2004;17:209-18. doi:10.1111/j.1365277X.2004.00520x

47 Braam LA, Ocké MC, Bueno-de-Mesquita HB, Seidell JC. Determinants of obesity-related underreporting of energy intake. Am J Epidemiol 1998;147:1081-6. doi:10.1093/oxfordjournals.aje.a009402

48 Hall KD, Guo J. Obesity energetics: body weight regulation and the effects of diet composition.
Gastroenterology 2017;152:1718-1727.e3. doi:10.1053/j.gastro.2017.01.052

49 Johnston BC, Kanters S, Bandayrel K, et al. Comparison of weight loss among named diet programs in overweight and obese adults: a metaanalysis. JAMA 2014;312:923-33. doi:10.1001/ jama.2014.10397

50 Tobias DK, Chen M, Manson JE, Ludwig DS, Willett W, Hu FB. Effect of low-fat diet interventions versus other diet interventions on long-term weight change in adults: a systematic review and meta-analysis. Lancet Diabetes Endocrinol 2015;3:968-79. doi:10.1016/ S2213-8587(15)00367-8

51 Hashimoto Y, Fukuda T, Oyabu C, et al. Impact of low-carbohydrate diet on body composition: metaanalysis of randomized controlled studies. Obes Rev 2016;17:499-509. doi:10.1111/obr.12405

52 Sackner-Bernstein J, Kanter D, Kaul S. Dietary intervention for overweight and obese adults: comparison of low-carbohydrate and low-fat diets. A meta-analysis. PLoS One 2015;10:e0139817. doi:10.1371/journal.pone.0139817

53 Olsson KE, Saltin B. Variation in total body water with muscle glycogen changes in man. Acta Physiol Scand 1970;80:11-8. doi:10.1111/j.1748-1716.1970.tb04764.x

54 Churuangsuk, et al. 2018.

55 Hjorth MF, Ritz C, Blaak EE, et al. Pretreatment fasting plasma glucose and insulin modify dietary weight loss success: results from 3 randomized clinical trials. Am J Clin Nutr 2017;106:499-505. . doi:10.3945/ ajcn.117.155200

56 Pittas AG, Das SK, Hajduk CL, et al. A low-glycemic load diet facilitates greater weight loss in overweight adults with high insulin secretion but not in overweight adults with low insulin secretion in the CALERIE Trial. Diabetes Care 2005;28:2939-41. doi:10.2337/ diacare.28.12.2939

57 Simpson HC, Simpson RW, Lousley S, et al. A high carbohydrate leguminous fibre diet improves al aspects of diabetic control. Lancet 1981;1:1-5. doi:10.1016/S0140-6736(81)90112-4

58 Lousley SE, Jones DB, Slaughter P, Carter RD, Jelfs R, Mann JI. High carbohydrate-high fibre diets in poorly controlled diabetes. Diabet Med 1984;1:21-5. doi:10.1111/j.1464-5491.1984.tb01916.x

59 Jung $\mathrm{CH}$, Choi KM. Impact of High-Carbohydrate Diet on Metabolic Parameters in Patients with Type 2 Diabetes. Nutrients 2017;9:E322. doi:10.3390/ nu9040322.

60 Riccardi G, Rivellese AA. Effects of dietary fiber and carbohydrate on glucose and lipoprotein metabolism in diabetic patients. Diabetes Care 1991;14:1115-25. doi:10.2337/diacare.14.12.1115

61 Gardner CD, Trepanowski JF, Del Gobbo LC, et al. Effect of low-fat vs low-carbohydrate diet on 12-month weight loss in overweight adults and the association with genotype pattern or insulin secretion: The DIETFITS Randomized Clinical Trial. JAMA 2018;319:667-79. doi:10.1001/ jama.2018.0245

62 Hjorth MF, Due A, Larsen TM, Astrup A pretreatment fasting plasma glucose modifies dietary weight loss maintenance success: results from a stratified RCT. Obesity (Silver Spring) 2017;25:2045-8. doi:10.1002/oby. 22004

63 Hjorth M, Blædel T, Bendtsen L, et al. Prevotella-toBacteroides ratio predicts body weight and fat loss success on 24-week diets varying in macronutrient composition and dietary fiber: results from a post-hoc analysis. Int J Obes 2005;2018.

64 Valders AM, Walter J, Segal E, Spector TD. Role of the gut microbiota in nutrition and health. BMJ 2018;361:k2179.

65 Pedersen HK, Gudmundsdottir V, Nielsen HB, et al, MetaHIT Consortium. Human gut microbes impact host serum metabolome and insulin sensitivity. Nature 2016;535:376-81. doi:10.1038/nature18646

66 Chen T, Long W, Zhang C, Liu S, Zhao L, Hamaker BR. Fiber-utilizing capacity varies in Prevotellaversus Bacteroides-dominated gut microbiota. Sci Rep 2017;7:2594. . doi:10.1038/s41598-01702995-4

67 Hjorth MF, Roager HM, Larsen TM, et al. Pre-treatment microbial Prevotella-to-Bacteroides ratio, determines body fat loss success during a 6-month randomized controlled diet intervention. Int J Obes 2017. [Epub ahead of print.]. doi:10.1038/ijo.2017.220.

68 Gamarra B, Howcroft R, McCall A, et al. 5000 years of dietary variations of prehistoric farmers in the Great Hungarian Plain. PLoS One 2018;13:e0197214. doi:10.1371/journal.pone.0197214

69 Kaplan H, Thompson RC, Trumble BC, et al. Coronary atherosclerosis in indigenous South American Tsimane: a cross-sectional cohort study. Lancet 2017;389:1730-9. doi:10.1016/S01406736(17)30752-3

70 Wallner SJ, Luschnigg N, Schnedl WJ, et al. Body fat distribution of overweight females with a history of weight cycling. Int J Obes Relat Metab Disord 2004;28:1143-8. doi:10.1038/sj.ijo.0802736

71 Urban LE, Lichtenstein AH, Gary CE, et al. The energy content of restaurant foods without stated calorie information. JAMA Intern Med 2013;173:1292-9. doi:10.1001/jamainternmed.2013.6163

72 Lean MEJ. Trading regulations and health foods. BMJ 2008;337:a2408. doi:10.1136/bmj.a2408

73 Lean M, Lara J, Hill JO. ABC of obesity. Strategies for preventing obesity. BMJ 2006;333:959-62. doi:10.1136/bmj.333.7575.959

Cite this as: BMJ 2018;361:k2538 http://dx.doi.org/10.1136/bmj.k2538

This is an Open Access article distributed in accordance with the Creative Commons Attribution Non Commercial (CC BY-NC 4.0) license, which permits others to distribute, remix, adapt, build upon this work non-commercially, and license their derivative works on different terms, provided the original work is properly cited and the use is non-commercial. See: http://creativecommons.org/licenses/by-nc/4.0/ 